\title{
Optimal Energy Management for Series-Parallel Hybrid Electric City Bus Based on Improved Genetic Algorithm
}

\author{
Bingzhan ZHANG*,**, Guodong ZHAO*, Yong HUANG**, Yaoyao NI*, Mingming QIU*** \\ *Hefei University of Technology, School of Automotive and Traffic Engineering, Hefei, 230009, China, E-mail: E-mail: \\ zhangbingzhan@hfut.edu.cn \\ **Hefei University of Technology, AnHui Key Laboratory of Digit Design and Manufacture, Hefei, 230009, China, \\ E-mail: 373970245@qq.com (Corresponding author) \\ ***Hefei University of Technology, School of Mechanical Engineering, Hefei, 230009, China, \\ E-mail: hfutqmm@hfut.edu.cn
}

cross $^{\text {ref }}$ http://dx.doi.org/10.5755/j01.mech.26.3.24133

\section{Introduction}

In recent years, due to the better performance of fuel economy and emission compared with the traditional vehicles, hybrid electric vehicles (HEV) become the most promising vehicle models. HEV have multiple power sources, when the configurations and parameters of $\mathrm{HEV}$ have been determined, the performance of HEV will heavily dependent on energy management strategy (EMS) [1-3].

The optimization of energy management strategy for HEV is a highly nonlinear optimization problem [4-5]. The methods divided into two categories: gradient-based algorithm and non-gradient algorithm. Gradient-based search methods require that the objective function be continuous, differentiable, and satisfy the Lipschitz condition [6]. This method has slower convergence speed, lower the probability of the global value. Non-gradient based algorithm could calculate the global optimal solution without the gradient information of the objective function [7-9]. GA has the stronger ability of global searching quickly and parallel computing, so genetic algorithm is suitable for solving the optimization problem of HEV [10-11].

Although genetic algorithm can solve the HEV parameter optimization problems, it still has limitation in the process of evolution [12-13]. During evolution process, the method of fixed value adopted in the crossover probability and mutation probability cannot meet the demand of crossover probability and mutation probability in different stage. In this paper, the calculation formulas of crossover probability and mutation probability with the adaptive changes of fitness and iteration times are proposed, and the elite retention strategy is used to select the next generation, which not only accelerates the convergence rate of genetic algorithm, but also improves the optimization quality.

This paper takes a series-parallel hybrid electric bus (SPHEB) as the research object. First, the energy management strategy is designed. Then, the vehicle simulation model is built based on simulation software CRUISE, and the improvement of the traditional genetic algorithm is proposed which is verified the effectiveness by finding the global minimum through the Ackley function. Finally, the vehicle fuel economy is taken as the optimization objective, and the improved genetic algorithm is used to optimize the relevant parameters of the energy management strategy for different operating conditions. The results show that the fuel economy is markedly improved after optimization.

\section{Principle of hybrid power system}

\subsection{Configurations and models of HEB}

In this paper, a series-parallel hybrid electric bus (SPHEB) with dual-motor coaxial structure is studied, the configurations of SPHEB as shown in Fig. 1. The hybrid power system is mainly composed of engine, ISG motor, main motor, electronically controlled clutch, power battery pack and the final drive, etc. Vehicle control unit (VCU) switch the mode between series and parallel modes by controlling the clutch. Communication with engine controller, main motor controller and ISG motor controller is realized through CAN-bus, and torque and speed control of engine, main motor and ISG motor are completed.

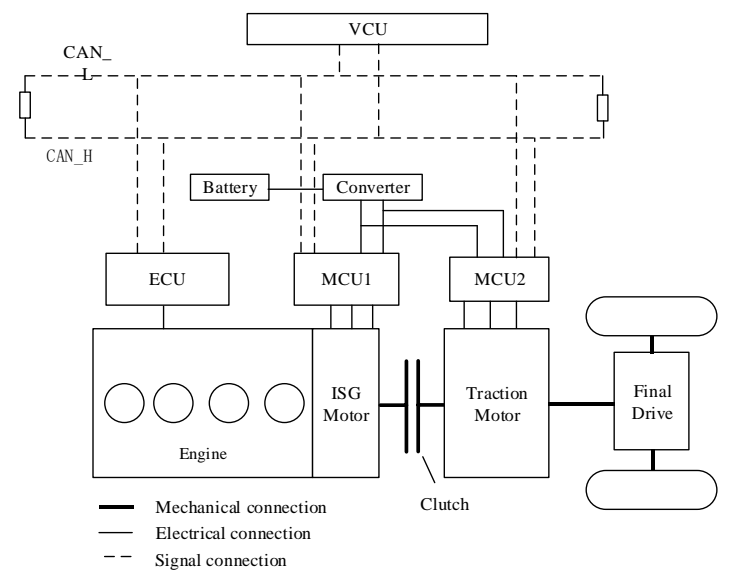

Fig. 1 SPHEB configuration

Table 1

Basic parameters for SPHEB models

\begin{tabular}{|l|c|c|}
\hline Parameters & & Values \\
\hline Curb weight & $m, \mathrm{~kg}$ & 11900 \\
\hline Full mass & $M, \mathrm{~kg}$ & 15900 \\
\hline Frontal area & $A, \mathrm{~m}^{2}$ & 6.93 \\
\hline Air drag coefficient & $C_{D}$ & 0.55 \\
\hline Wheel radius & $r, \mathrm{~m}$ & 0.512 \\
\hline Maximum power of engine & $P_{e}, \mathrm{~kW}$ & 155 \\
\hline Maximum power of main motor & $P_{m}, \mathrm{~kW}$ & 135 \\
\hline Maximum power of ISG motor & $P i, \mathrm{~kW}$ & 72 \\
\hline Battery capacity & $Q, \mathrm{Ah}$ & 50 \\
\hline Final ratio & $i_{0}$ & 6.14 \\
\hline
\end{tabular}


This kind of hybrid structure with double motor coaxial combines the advantages of series and parallel hybrid vehicles, can achieve the best design goal of gas consumption and emission. The basic parameters are shown in Table 1 .

\subsection{Vehicle modeling}

\subsubsection{Vehicle dynamic model}

Based on the vehicle parameters and the vehicle velocity, the vehicle traction power is obtained as the following Eq. (1):

$$
P_{\mathrm{t}}=\frac{v}{1000}\left(m g f \cos \alpha+\frac{C_{D} A}{21.15} v^{2}+m g \sin \alpha+m a\right) \text {, }
$$

where: $m$ is the vehicle mass, $\mathrm{kg}$; $v$ is the vehicle velocity, $\mathrm{m} / \mathrm{s} ; g$ is the gravity acceleration, $\mathrm{m} / \mathrm{s}^{2} ; f$ is the rolling resistance coefficient; $C_{D}$ is the aerodynamic drag coefficient; $A$ is front area of the vehicle, $\mathrm{m}^{2} ; \alpha$ is the road slope angle; $a$ is the vehicle acceleration.

\subsubsection{ICE model}

Fig. 2 shows a typical efficiency map of an ICE and indicates the fuel economy characteristics as a function of $I C E$ speed and torque. The map represents the maximum $I C E$ torque boundary and fuel consumption contours.

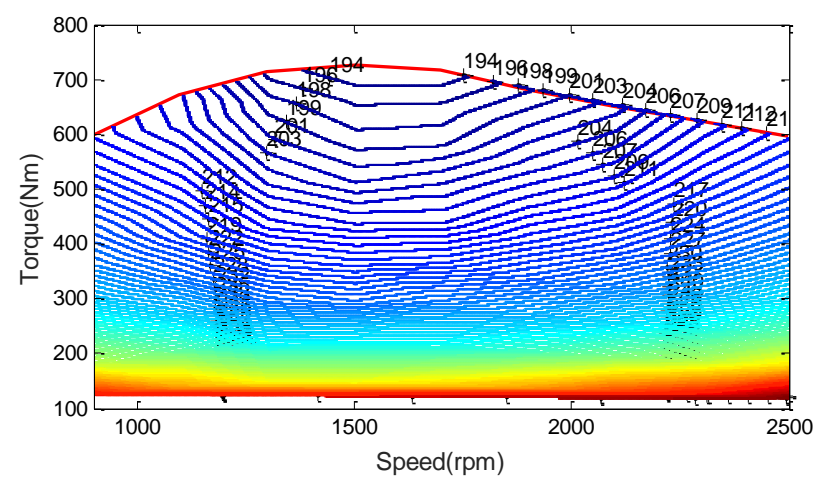

Fig. 2 A typical efficiency map of an ICE

Based on the ICE speed and the ICE torque lookup table, the $I C E$ fuel rate $\dot{m}_{f}$ is obtained as the following Eq. (2):

$$
\dot{m}_{f}=f\left(T_{I C E}, \omega_{I C E}\right) \text {, }
$$

where: $T_{I C E}$ denotes ICE torque $(\mathrm{Nm})$, and $\omega_{I C E}$ is the ICE speed $(\mathrm{rad} / \mathrm{s})$.

\subsubsection{Battery model}

The input signal of the battery model is the vehicle demanded power while the outputs are the battery $S O C$, current, terminal voltage, and actual power of the battery pack.

The battery SOC is one of the most important parameters for the vehicle and battery energy management systems that can potentially provide the information regard- ing the amount of energy stored in the battery to the controller. The battery SOC highly influences the battery life cycle. There are several methods reported for evaluating the battery $S O C$ such as the ampere-hour integral, open circuit voltage and neural network methods. In this research, the ampere-hour integral method is employed for estimating the battery $S O C$, which based on the control strategy, determines the vehicle operation mode. The battery $S O C$ is evaluated as the following Eq. (3):

$$
\operatorname{SOC}(t)=S_{O C C_{i n i}}-\frac{1}{Q} \int_{0}^{t} \eta I_{\text {out }}(t) d t
$$

where: $S O C_{i n i}$ denotes the initial value of $S O C, Q$ is the battery capacity, and $\eta$ is the battery columbic efficiency.

The battery current $I_{\text {out }}$ can be calculated as the following Eq. (4):

$$
I_{o u t}=\frac{V_{o c}-\sqrt{V_{o c}^{2}-4 R_{b} P_{d}}}{2 R_{b}}
$$

where: $V_{o c}$ and $R_{b}$ are the open circuit voltage and internal resistance of the battery, $P_{d}$ is the battery power demand.

\subsubsection{EM model}

The input power of the EM model is the battery power during motoring mode of operation or battery charging power during generating mode of operation that is provided by the $I C E$ or braking. According to the efficiency map of the EM in motoring mode and generating mode that is modelled by using a lookup table indexed by torque and speed in the Cruise software, the EM power loss is obtained. Therefore, the EM power is calculated by deducting the power loss from the supplied power. Accordingly, the EM output torque $T_{m}$ is obtained when the EM power is divided by the EM rotational speed $\omega_{m}$.

\section{Energy management strategy}

\subsection{Operation mode analysis}

There are three ways of power transmission in the system including pure electric, series, and parallel mode. When the clutch is separated, the requested driving torque of the vehicle is all provided by the main motor, which realizes the pure electric function. On the basis of pure electric, the engine can charge the power battery pack through ISG motor according to the need of power battery pack charging, so as to realize series driving. When the clutch is engaged, the requested torque is distributed by the engine, ISG motor and main motor according to the current driving cycle, which realizes the parallel function.

According to the above analysis, the operating modes of this hybrid city bus mainly include: pure electric drive mode, series power generation drive mode, engine drive alone mode, driving charging mode, combined drive mode and regenerative braking mode. 


\subsection{Rule-based energy management strategy design}

\subsubsection{Pure electric drive mode}

When the real-time speed is lower than the minimum speed at which the engine can directly drive the vehicle $\left(v<v_{0}\right)$, state of charge is no less than the lower limit of battery working area $\left(S O C \geq S O C_{L}\right)$, and the demand torque is no less than $0\left(T_{\text {req }} \geq 0\right)$, or when the real-time speed is no less than he minimum speed at which the engine can directly drive the vehicle $\left(v \geq v_{0}\right)$, state of charge is no less than the lower limit of battery working area $\left(S O C \geq S O C_{L}\right)$, and the demand torque is higher than 0 and lower than the lower limit of the engine efficient zone $\left(0<T_{r e q}<T_{e_{-} \min }\right)$, pure electric drive mode is activated. Where: $T_{e_{-} \min }$ denotes the lower limit of the engine efficient zone $T_{e_{-} \min }=T_{e_{-} \max } \times \eta_{\min } ; S O C_{L}$ denotes the lower limit of battery working area; $v_{0}$ is the minimum speed at which the engine can directly drive the vehicle, and its value should be greater than the speed corresponding to the engine idle speed.

\subsubsection{Series power generation drive mode}

When the real-time speed is lower than the minimum speed at which the engine can directly drive the vehicle $\left(v<v_{0}\right)$, state of charge is lower than the lower limit of battery working area $\left(S O C<S O C_{L}\right)$, and the demand torque is no less than $O\left(T_{\text {req }} \geq 0\right)$, series power generation drive mode is activated.

\subsubsection{Engine drive alone mode}

When the real-time speed is no less than the minimum speed at which the engine can directly drive the vehicle $\left(v \geq v_{0}\right)$, state of charge is no less than the lower limit of battery working area $\left(S O C<S O C_{L}\right)$, the demand torque is no less than the lower limit of the engine efficient zone and no greater than the upper bound of the engine efficient zone $\left(T_{e_{-} \min } \leq T_{\text {req }} \leq T_{e_{-} \max }\right)$, or when the real-time speed is no less than the minimum speed at which the engine can directly drive the vehicle $\left(v \geq v_{0}\right)$, state of charge is lower than the lower limit of battery working area $\left(S O C<S O C_{L}\right)$, and the demand torque is greater than the upper bound of the engine efficient zone $\left(T_{\text {req }}>T_{e_{-} \max }\right)$, engine drive alone mode is activated.

\subsubsection{Driving charging mode}

\subsubsection{Driving charging mode 1}

When the real-time speed is no less than the minimum speed at which the engine can directly drive the vehicle $\left(v \geq v_{0}\right)$, state of charge is lower than the lower limit of battery working area $\left(S O C<S O C_{L}\right)$, the demand torque is greater than 0 and less than the lower limit of the engine efficient zone $\left(0<T_{\text {req }}<T_{e_{-} \text {min }}\right)$, driving charging mode 1 is activated.

\subsubsection{Driving charging mode 2}

When the real-time speed is no less than the minimum speed at which the engine can directly drive the vehicle $\left(v \geq v_{0}\right)$, state of charge is less than the lower limit of battery working area $\left(S O C<S O C_{L}\right)$, and the demand torque is no less than the lower limit of the engine efficient zone and no greater than the upper bound of the engine efficient zone $\left(T_{e_{-} \min } \leq T_{\text {req }} \leq T_{e_{-} \max }\right)$, driving charging mode 2 is activated.

\subsubsection{Combined drive mode}

When the real-time speed is no less than the minimum speed at which the engine can directly drive the vehicle $\left(v \geq v_{0}\right)$, state of charge is no less than the lower limit of battery working area $\left(S O C<S O C_{L}\right)$, and the demand torque is greater than the upper bound of the engine efficient zone $\left(T_{r e q}>T_{e_{-} \max }\right)$, combined drive mode is activated.

\subsubsection{ISG starting engine mode}

When the engine control signal equals $1\left(S_{e}=1\right)$ and the state of engine equals $0\left(\right.$ State $\left._{\text {eng }}=0\right)$, ISG starting engine mode is activated. Where: State $_{\text {eng }}$ is the state of engine; 0 denotes the state of closure and 1 denotes the state of opening.

\subsubsection{Clutch closure control mode}

When the state of engine equals 1 , the state of clutch equals 1 and the engine control signal equals 0 , clutch closure control mode is activated. Where: State $c$ is the state of clutch; 0 denotes closure state and 1 denotes separation state.

During energy management strategy modelling, in order to prevent frequent switching between the pure electric drive mode and the series power generation drive mode caused by frequent fluctuation of the control quantity near the threshold, the battery $S O C$ return difference is adopted in this paper, and the mode judgment process is shown in Fig. 3.

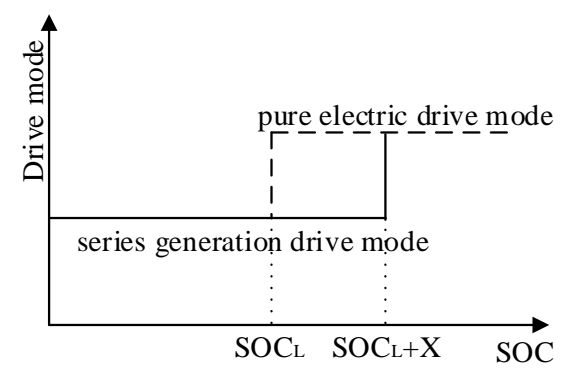

Fig. 3 Switching process between pure electric drive mode and series power generation drive mode

When the vehicle works in the series power generation drive mode, the engine drives the ISG motor to generate electricity. When the battery $S O C$ is greater than $S O C_{L}$, the vehicle's operating mode does not change. The vehicle does not switch to pure electric drive mode until $S O C$ is higher than $S O C_{L}+X$. Similarly, the judgment process of 
switching from pure electric drive mode to series drive mode is the same.

\subsection{Simulation results}

Two consecutive Chinese typical city bus driving cycle $(\mathrm{CCBC})$ is selected as driving scenario. The vehicle carries $65 \%$ of the load, and the difference between the target speed and the actual speed is shown in Fig. 4. Except for a few data points, the speed difference of most data points (accounting for $99.15 \%$ of the total data points) is within $\pm 1 \mathrm{~km} / \mathrm{h}$, indicating that the speed follows well and the developed energy management strategy is feasible.

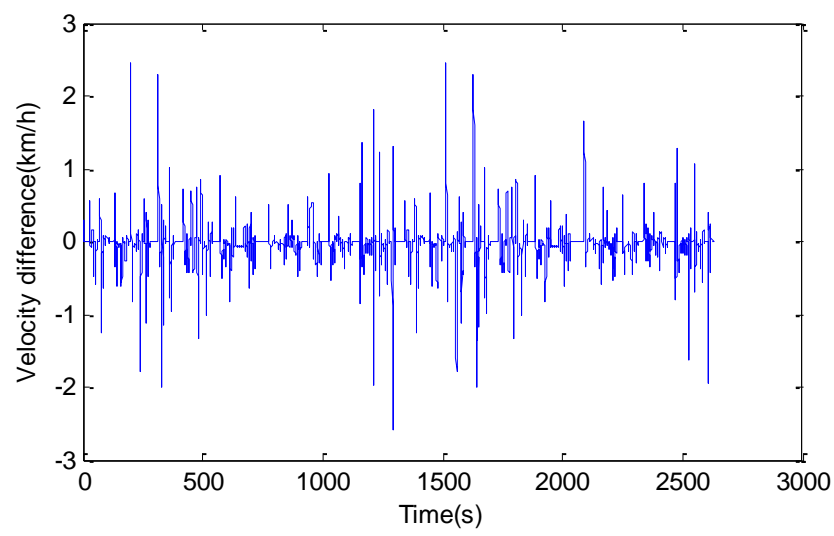

Fig. 4 Change of velocity difference of cycle driving

The performance indicators and design objectives obtained by simulation are shown in Table 2 .

Table 2

Simulation results of the performance indicators

\begin{tabular}{|l|c|c|}
\hline performance indicators & $\begin{array}{l}\text { simulation } \\
\text { results }\end{array}$ & $\begin{array}{c}\text { design } \\
\text { values }\end{array}$ \\
\hline Maximum speed $/ \mathrm{km} / \mathrm{h}$ & 78.4 & $\geq 70$ \\
\hline $\begin{array}{l}0-50 \mathrm{~km} / \mathrm{h} \\
\text { acceleration time } / \mathrm{s}\end{array}$ & 12.3 & $\leq 13$ \\
\hline Maximum grade ability $/ \%$ & 15 & $\leq 15$ \\
\hline $\begin{array}{l}\text { Gas consumption of cycle condi- } \\
\text { tion } / \mathrm{kg} / 100 \mathrm{~km}\end{array}$ & 20.68 & $\leq 22$ \\
\hline
\end{tabular}

Fig. 5 shows the acceleration changes of the above two acceleration processes. The acceleration process with clutch closure control mode is called acceleration process 1 , and the one without is called acceleration process 2 .

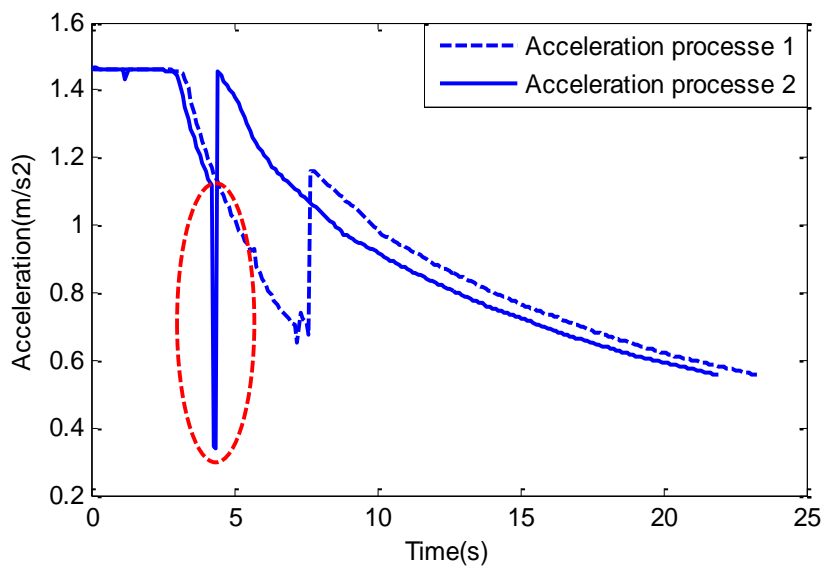

Fig. 5 Acceleration changes of two acceleration processes
Since there is no clutch closure control mode in the acceleration process 2 , the clutch is on-off static control, which engages instantaneously. Due to the rotary inertia of the engine and ISG motor, the speed difference between the active end and the driven end of the clutch will produce a large drive or brake torque when the clutch is engaged, resulting in sudden acceleration, as shown in the oval part in Fig. 5. But with the clutch closure control mode, the abrupt acceleration is improved.

\section{Optimization algorithm}

\subsection{Genetic algorithm improvement}

The traditional genetic algorithm adopts fixed crossover probability and mutation probability in the process of evolution, which may lead to reducing the rate of convergence of the algorithm and even converging to the local optimal solution. The crossover probability and mutation probability formulas with adaptive changes of fitness and iteration times are introduced, which can accelerate the convergence of genetic algorithm and improve its optimization ability.

The specific ideas to improve the algorithm are as follows:

1) In the early stage of evolution, larger crossover probability and mutation probability should be adopted to generate more new individuals, so that the search region can spread rapidly within the whole definition domain. Else, the global convergence of the algorithm and overcome precocity should be improved.

2) In the later stage of evolution, the crossover probability and mutation probability should be reduced to prevent the loss of some excellent genes in the parent generation, and the algorithm efficiency and local search ability should be improved to accelerate the convergence.

3) When the average fitness of the population is poor, the probability of variation should be increased to improve the possibility of producing excellent individuals, while when the average value of fitness of the population is close to the optimal solution, the probability of mutation should be reduced.

From what has been discussed above, the proposed crossover probability and mutation probability formulas with adaptive changes of evolutionary generation and fitness value are shown in Eq. (5):

$$
\left\{\begin{array}{l}
P_{\mathrm{c}}=P_{c 0} \sqrt{1-\left(t / t_{\text {max }}\right)^{2}} \\
P_{\mathrm{m}}=P_{m 0}\left(1-t / t_{\text {max }}\right)+P_{m 1}\left(1-f_{a v} / f_{\text {max }}\right)
\end{array},\right.
$$

where: $P_{c 0}$ denotes initial crossover probability; $t$ denotes current evolutionary generation; $t_{\max }$ denotes the total evolutionary generation; $P_{m 0}$ denotes initial mutation probability; $P_{m 1}$ denotes the minimum allowed by mutation probability; $f_{a v}$ denotes the average fitness value of the current population, and $f_{\max }$ denotes the maximum fitness value in population.

\subsection{The verification of the improved algorithm}

The improved genetic algorithm is tested by the typical minimized Ackley function. Ackley function is a type of continuous experimental function which is got by 
the superposition of exponential function moderate amplification of cosine function. The function expression takes the following Eq. (6) mathematical form:

$$
\begin{aligned}
& F(x)=20+\exp (1)-20 \exp \left[-0.2 \sqrt{\frac{1}{n}} \sum_{i=1}^{n} x_{i}^{2}\right]- \\
& -\exp \left[\frac{1}{n} \sum_{i=1}^{n} \cos \left(2 \pi x_{i}\right)\right],
\end{aligned}
$$

where: $-10 \leq x_{i} \leq 10(i=1 \ldots n), n=2$, the three-dimensional diagram is shown in Fig. 6. The Ackley function takes the only global minimum of 0 at $(0,0)$.

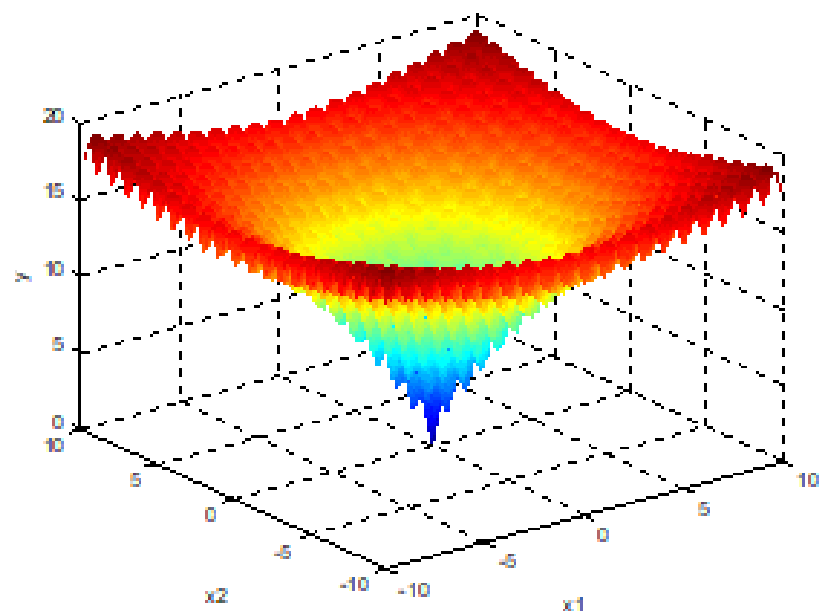

Fig. 6 The three-dimensional diagram of Ackley function

Since the initial population is generated randomly, it has a certain impact on the results. In order to reduce the impact caused by this randomness, the parameter settings are shown in Table 3. Each algorithm is calculated 10 times and takes the average value. The comparison of results is shown in Fig. 7.

Table 3

Parameter settings

\begin{tabular}{|l|c|c|}
\hline Parameters & $\begin{array}{l}\text { Traditional } \\
\text { genetic algo- } \\
\text { rithm }\end{array}$ & $\begin{array}{l}\text { The improved } \\
\text { genetic algo- } \\
\text { rithm }\end{array}$ \\
\hline $\begin{array}{l}\text { Evolutionary } \\
\text { generations }\end{array}$ & 100 & 100 \\
\hline Population size & 20 & 20 \\
\hline $\begin{array}{l}\text { Crossover } \\
\text { probability }\end{array}$ & 0.5 & - \\
\hline $\begin{array}{l}\text { Mutation } \\
\text { probability }\end{array}$ & 0.1 & 1.0 \\
\hline $\begin{array}{l}\text { Initial crossover prob- } \\
\text { ability }\end{array}$ & - & 1.0 \\
\hline $\begin{array}{l}\text { Initial mutation prob- } \\
\text { ability }\end{array}$ & - & 0.01 \\
\hline $\begin{array}{l}\text { Minimum } \\
\text { mutation probability }\end{array}$ & - & \\
\hline
\end{tabular}

After comparison, you can see that both of the search results are relatively close to the global minimum value 0 . However, by contrast with the traditional genetic algorithm, convergence speed and optimization quality of the improved genetic algorithm are better. To some extent, the improved genetic algorithm is effective, and the improved genetic algorithm is feasible in searching global optimal solution.

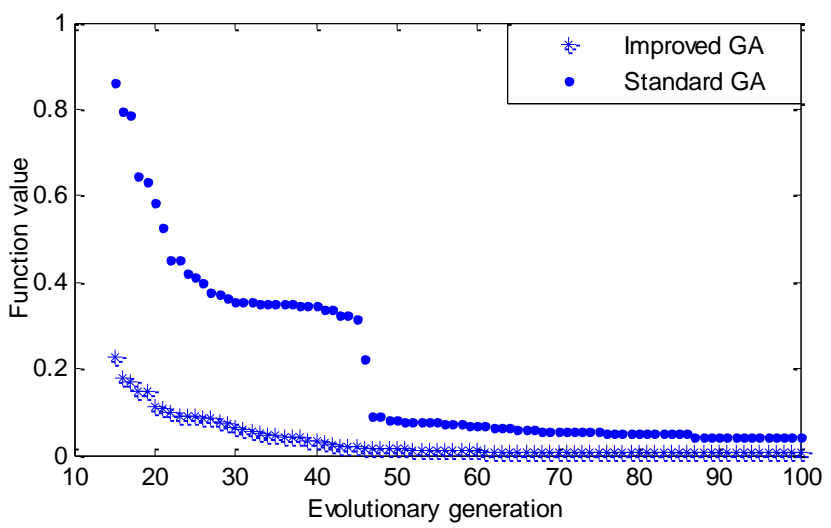

Fig. 7 Comparison between traditional genetic algorithm and improved genetic algorithm

\section{Parameter optimization based on improved genetic al- gorithm}

\subsection{Optimization objective}

In this paper, the control strategy parameters are optimized on the premise that the vehicle power components are determined. Accordingly, the optimization objective of this paper is to reduce the fuel consumption of the vehicle as much as possible. Therefore, the optimization objective function $f(x)$ is obtained as the following Eq. (7):

$$
f(x)=\min [\text { fuel }(X)], X \in \Omega,
$$

where: fuel $(x)$ denotes fuel consumption per hundred kilometres and its unit is $L / 100 \mathrm{~km}$; $X$ denotes vector which includes some relevant parameters of control strategy; $\Omega$ is the possible solution space and it defines the upper and lower bounds of optimization parameters.

\subsection{Optimization parameters}

Only the relevant parameters that have a great impact on vehicle fuel economy can be selected for optimization, which is in line with the actual situation. The following six parameters are selected as optimization parameters in this paper: lower limit coefficient of engine efficiency area $\eta_{\min }$, the minimum speed $V_{0}$ with which engine can directly drive the vehicle、 charging factor $K_{1}$ of driving charging mode 1 . Charging factor $K_{2}$ of driving charging mode 2, $S O C$ target equilibrium upper limit $S O C_{H}$ and the factor of $S O C$ workspace $\triangle S O C$.

The lower limit coefficient of engine efficiency area $\eta_{\min }$ determines the lower limit of engine efficiency working area, which affects the operating range and economy. The minimum speed $V_{0}$ that engine can directly drive the vehicle affects the minimum speed when the engine directly drives the vehicle, and the rotate speed has a great influence on the economy and emission of the engine, especially in the condition of low rotate speed. The charging factor $K_{1}$ and $K_{2}$ are related to the working point of the engine under the driving charging mode. The target lower limit 
$S O C_{L}$ of battery $S O C$ is determined by downward fluctuation $\triangle S O C$ of the target upper limit $S O C_{H}$. The optimization parameters and their value ranges are shown in Table 4. In consideration of the actual situation, the parameters in Table 4 are set for precision. $\eta_{\min }$ is set to two decimal places. $V_{0}, K_{1}$ and $K_{2}$ are set to one decimal place. $S O C_{H}$ and $\triangle S O C$ are set to three decimal places.

Table 4

Optimization parameters and their value ranges

\begin{tabular}{|c|c|c|}
\hline Parameters & Parameter specification & Value range \\
\hline$\eta_{\min }$ & $\begin{array}{c}\text { The lower limit coefficient of } \\
\text { engine efficiency area }\end{array}$ & $0.3,0.4$ \\
\hline$V_{0}$ & $\begin{array}{c}\text { The minimum speed that en- } \\
\text { gine can directly drive the ve- } \\
\text { hicle }\end{array}$ & 25,33 \\
\hline$K_{1}$ & $\begin{array}{c}\text { Charging factor of driving } \\
\text { charging mode } 1\end{array}$ & 10,30 \\
\hline$K_{2}$ & $\begin{array}{c}\text { Charging factor of driving } \\
\text { charging mode } 2\end{array}$ & 10,30 \\
\hline$S O C_{H}$ & $\begin{array}{c}\text { SOC target equilibrium upper } \\
\text { limit }\end{array}$ & $0.3,0.5$ \\
\hline$\triangle S O C$ & The factor of SOC workspace & $0.03,0.05$ \\
\hline
\end{tabular}

\subsection{Optimization model}

In this paper, the improved genetic algorithm is combined with Matlab/Simulink, and the simulation model of control strategy parameter optimization of hybrid electric city bus is established by using the model in the loop. As is shown in Fig. 8 to achieve parameter optimization.

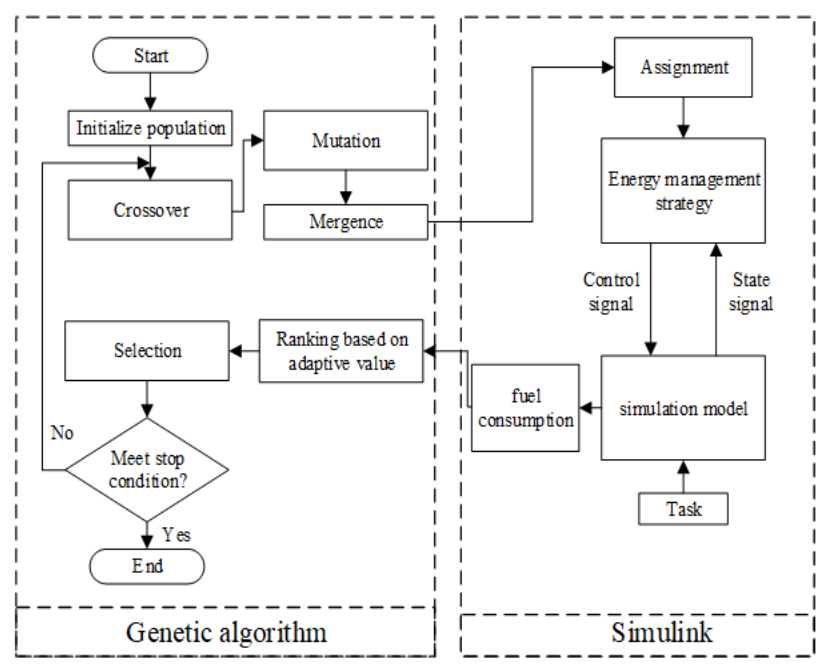

Fig. 8 The flow diagram of parameters optimization of energy management strategy based on genetic algorithm

The specific optimization process is as follows:

1) $N$ individuals are randomly generated within the feasible region of the optimization variable $X$ as the initial population.

2) According to the adaptive crossover probability formula, calculating the crossover probability and performing the crossover operation.

3) According to the adaptive mutation probability formula, calculating the mutation probability and carrying out the mutation operation.

4) The parent generation and the offspring obtained through crossover and mutation are compounded into a population with $2 N$ individuals, and the optimal parameters in the control strategy model are assigned successively. By running the simulation model, the comprehensive consumption of natural gas of 100 kilometres is achieved.

5) The values of fitness function are calculated based on the returned performance indicators and sorted in the order of the values of fitness from large to small.

6) The selection operations are carried out and the first $\mathrm{N}$ of the $2 \mathrm{~N}$ sorted individuals are selected as the next generation population.

7) Using the evolutionary generation as the termination criterion. If the evolutionary generation is less than the set value, then return to step 2). If satisfied, terminate the program and return the individual with the maximum fitness value obtained during evolution as the optimal solution.

\subsection{Analysis of optimization results}

This paper uses different testing cycles to optimize and compares the solutions obtained by different optimization methods. The first one takes the single working condition of 8 repeated typical bus driving scenarios in Chinese cities as the testing cycles, which is called optimization method 1. The second method selects the comprehensive driving scenarios successively arranged and jointed by CCBC scenario, UDC scenario, Manhattan scenario and Ja1015 scenario as the testing cycles, which is called optimization method 2.

The initial SOC of both optimization methods are set to 0.6 , the population size is set to 20 , and the evolutionary generation is set to 80 . The changing curve of the comprehensive gas consumption of the optimal individual in the population of optimization method 1 is shown in Fig. 9.

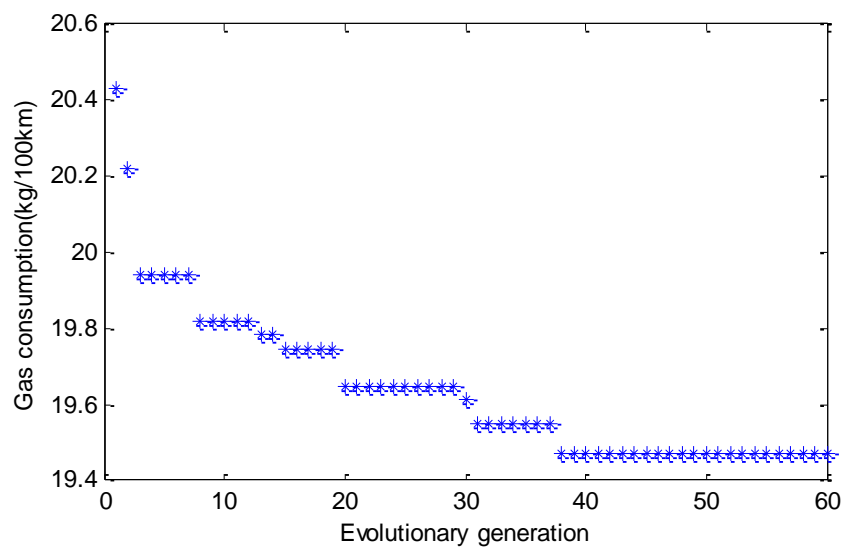

Fig. 9 The changing curve of the comprehensive gas consumption of the optimal individual in the population of optimization method 1

The changing curve of the comprehensive gas consumption of the optimal individual in the population of optimization method 2 is shown in Fig. 10.

Comparison of comprehensive gas consumption per hundred kilometres before and after optimization based on optimization method 1 and optimization method 2 are shown in Table 5, where A denotes The comprehensive gas consumption before optimization, B denotes The comprehensive gas consumption of the optimized value obtained by optimization method $1, \mathrm{C}$ denotes The comprehensive gas 
consumption of the optimized value obtained by optimization method 2.

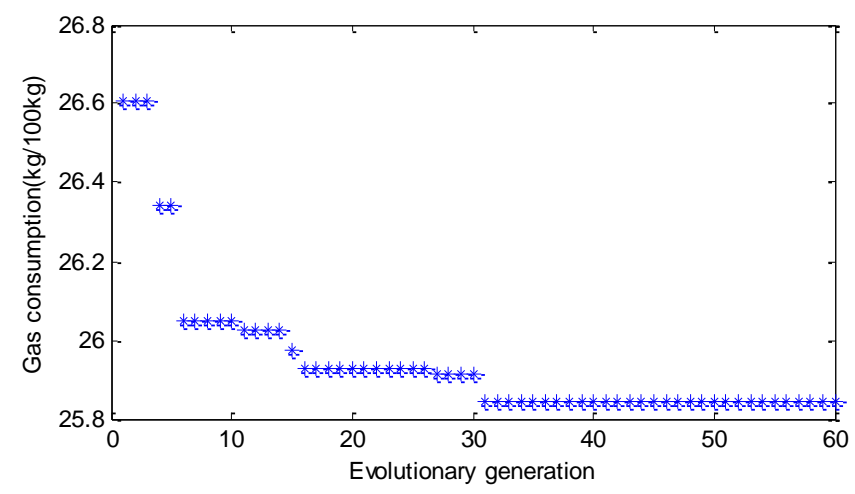

Fig. 10 The changing curve of the comprehensive gas consumption of the optimal individual in the population of optimization method 2

Table 5

Comparison of comprehensive gas consumption before and after optimization

\begin{tabular}{|c|c|c|c|c|}
\hline $\begin{array}{c}\text { Scenarios and } \\
\text { Gas consump- } \\
\text { tion }\end{array}$ & $\begin{array}{c}\text { CCBC } \\
\times 8\end{array}$ & $\begin{array}{c}\text { Comprehen- } \\
\text { sive } \\
\text { scenario }\end{array}$ & $\begin{array}{c}\text { UDC } \\
\times 10\end{array}$ & $\begin{array}{c}\text { Ja1015 } \\
\times 10\end{array}$ \\
\hline $\mathrm{A}(\mathrm{kg} / 100 \mathrm{~km})$ & 20.68 & 27.21 & 27.60 & 22.31 \\
\hline $\mathrm{B}(\mathrm{kg} / 100 \mathrm{~km})$ & 19.47 & 26.64 & 26.11 & 21.82 \\
\hline $\mathrm{C}(\mathrm{kg} / 100 \mathrm{~km})$ & 20.16 & 25.85 & 25.48 & 21.60 \\
\hline
\end{tabular}

It can be seen from Table 5 that the optimized value obtained by optimizing a certain testing cycle is the optimal one for the corresponding comprehensive gas consumption per hundred kilometres. Optimization method 1 improves the initial comprehensive gas consumption by $5.85 \%$ under CCBC cycle condition. Compared with before optimization, Optimization method 2 improves the comprehensive gas consumption by $4.89 \%$ under the comprehensive scenario. Under the UDC scenario and Ja1015 scenario, the fuel economy optimized by the two optimization methods has been improved in different degree, but in the degree of improvement, the optimization method based on the comprehensive scenario is better than the optimization method based on the single cycle. Else, Ftp72 and Modified_IDC_PC_LDV_ _BSII_man scenario in Cruise software working condition library were selected as the testing cycles.

The economic simulation results are shown in Table 6:

Table 6

The economic simulation results

\begin{tabular}{|l|l|c|}
\hline $\begin{array}{c}\text { Scenarios and } \\
\text { Gas consumption }\end{array}$ & $\begin{array}{l}\text { Ftp72 } \\
\text { scenario }\end{array}$ & $\begin{array}{c}\text { Modified_IDC_PC_LDV_BI_man scenario } \\
\text { _BSII_m }\end{array}$ \\
\hline $\mathrm{A}(\mathrm{kg} / 100 \mathrm{~km})$ & 32.87 & 27.21 \\
\hline $\mathrm{B}(\mathrm{kg} / 100 \mathrm{~km})$ & 30.41 & 27.66 \\
\hline $\mathrm{C}(\mathrm{kg} / 100 \mathrm{~km})$ & 29.47 & 23.57 \\
\hline
\end{tabular}

It can be seen from Table 6 that under Ftp72 scenario, the economy of the optimized value obtained by the two optimization methods is better than the initial value. But under Modified_IDC_PC_LDV_BSII_man scenario, the economy of the optimized value obtained by optimization method 1 is not as good as the initial value, which indicates that the optimized parameters based on specific working conditions may not have better economic performance under any working condition. At the same time, it shows that the optimized value based on the comprehensive scenario has better economy than the optimized value based on the single cycle under many scenarios, which indicates that the optimization method based on the comprehensive scenario is better than the optimization method based on the single cycle in terms of the adaptability of working condition.

\section{Conclusions}

Aiming at the deficiency of traditional genetic algorithm, the crossover probability and mutation probability of adaptive change with evolutionary generation and population fitness were introduced, and the improved genetic algorithm was tested by using Ackley function. The results show that compared with the traditional genetic algorithm, the improved genetic algorithm has better convergence speed and optimization quality. The improved genetic algorithm is applied to the parameters optimization of energy management strategy of series-parallel hybrid electric city bus. After optimization, both the economy of CCBC and the comprehensive scenario have been improved to a certain extent. Moreover, compared with the optimized value based on the single cycle, the optimized value based on the comprehensive scenario has better economy under various working conditions, which indicates that the optimization method based on the comprehensive scenario is better than the optimization method based on the single cycle in terms of the adaptability of working condition.

\section{Acknowledgments}

This work was supported by "the Fundamental Research Funds for the Central Universities of China (Grant No. PA2019GDPK0067) and National Key R \& D Plan for New Energy Vehicles (Grant No. 2017YFB0103200)”,

\section{References}

1. Ceraolo, M.; Donato, A. D.; Franceschi, G. 2008. A general approach to energy optimization of hybrid electric vehicles, IEEE Transactions on Vehicular Technology 57(3):1433-1441. https://doi.org/10.1109/TVT.2007.909268.

2. Stockar, S.; Marano, V.; Canova, M.; Canova, M.; Rizzoni, G. 2011. Energy- optimal control of plug-in hybrid electric vehicles for real-world driving cycles, IEEE Transactions on Vehicular Technology 60(7): 2949-2962. https://doi.org/10.1109/TVT.2011.2158565.

3. Hu, X.; Murgovski, N.; Johannesson, L. 2013. Energy efficiency analysis of a series plug-in hybrid electric bus with different energy management strategies and battery sizes, Applied Energy 111(4): 1001-1009. https://doi.org/10.1016/j.apenergy.2013.06.056.

4. Xiong, W. W.; Yin, C. L.; Zhang, Y.2009. Series-parallel hybrid vehicle control strategy design and optimization using real-valued genetic algorithm, Chinese Journal of Mechanical Engineering 22(6):862-868. https://doi.org/10.3901/CJME.2009.06.862.

5. Chen, Q. H.; Lin, T. L.; Ren, H. L. 2018. Parameters optimization and control strategy of power train systems in hybrid hydraulic excavators, Mechatronics 56:16-25. 
https://doi.org/10.1016/j.mechatronics.2018.10.003.

6. Tao, Q. H.; Huang, X. L.; Wang, S. N.; Li, L. 2016. Adaptive block coordinate direct algorithm, Journal of Global Optimization 69(4):797-822. https://doi.org/10.1007/s10898-017-0541-x.

7. Wang, B.; Xu, J.; Cao, B. G. Ning, B. 2017. Adaptive mode switch strategy based on simulated annealing optimization of a multi-mode hybrid energy storage system for electric vehicles, Applied Energy 194:596-608. https://doi.org/10.1016/j.apenergy.2016.05.030.

8. Saad-Nagger, H.; EI-Sattar. Ahmed, A. 2018. A novel control strategy for grid connected hybrid renewable energy systems using improved particle swarm optimization, Ain Shams Engineering Journal 9(4):2195-2214. https://doi.org/10.1016/j.asej.2017.03.009.

9. Zhang, Y.; Meng, D. W.; Zhou, M. L. 2014. Management strategy based on genetic algorithm optimization for PHEV, International Journal of Control and Automation 7(11): 399-408. https://doi.org/10.14257/ijca.2014.7.11.37.

10. Chen, Z.; Mi, C. C.; Xiong, R. 2014. Energy management of a power-split plug-in hybrid electric vehicle based on genetic algorithm and quadratic programming, Journal of Power Sources 248(7):416-426. https://doi.org/10.1016/j.jpowsour.2013.09.085.

11. Montazeri-Gh, M.; Poursamad, A.; Ghalichi, B. 2006. Application of genetic algorithm for optimization of control strategy in parallel hybrid electric vehicles, Journal of the Franklin Institute 343(4-5):420-435. https://doi.org/10.1016/j.jfranklin.2006.02.015.

12. Deng, Y, W.; Wang, Bing. J.; Zhang, S. A.; Han, W. 2013. Optimization of energy management strategy of PHEV based on chaos-genetic algorithm, Journal of Hunan University (Natural Sciences) 40(4):42-48. https://doi.org/10.1016/j.memsci.2013.06.012.

13. Hu, F.; Zhao, Z. G. 2010. Multi-Objective Optimization for Parameters of Energy Management Strategy of HEV Based on Improved NSGA-II, Applied Mechanics and Materials 29-32:912-917. https://doi.org/10.4028/www.scientific.net/AMM.2932.912 .

\author{
B. ZH. Zhang, G. D. Zhao, Y. Huang, Y. Y. Ni, \\ M. M. Qiu
}

\section{OPTIMAL ENERGY MANAGEMENT FOR SERIES-PARALLEL HYBRID ELECTRIC CITY BUS}

S u m m a r y

This paper aims at proposing an efficient energy management strategy of the series-parallel hybrid electric bus (SPHEB) by using improved genetic algorithm. Firstly, the energy management strategy based on the logical threshold value is developed. The simulation model considering the vehicle dynamic performance is established by the combination of Matlab and Cruise software. Then, an improved genetic algorithm based on adaptive crossover probability and mutation probability is proposed to solve local convergence and premature convergence. Eventually, Chinese typical city bus driving cycle and the composite driving cycle are considered to show the effectiveness of the proposed energy management strategy in terms of the fuel economy. The results indicate that the fuel consumption is improved by $5.85 \%$ and $5.01 \%$ respectively, and the parameters obtained by optimizing for the composite driving cycle are more adaptable to the driving conditions and have better economic performance in all driving scenarios.

Keyword: series-parallel hybrid electric city bus, optimize, energy management strategy, genetic algorithm.

Received September 02, 2019 Accepted June 02, 2020 